\title{
SOCIO-ECONOMIC AND LIVELIHOOD RELATED ISSUES OF CRAB COLLECTORS IN KOGGALA LAGOON IN GALLE SRI LANKA
}

\author{
Sandika $\mathrm{AL}^{1}$ and Hirimuthugoda $\mathrm{NY}^{2}$ \\ ${ }^{1}$ Department of Agricultural Economics \& Extension and ${ }^{2}$ Department of Animal Science, Faculty of \\ Agriculture, University of Ruhuna, Mapalana, Kamburupitiya, Sri Lanka
}

Accepted: 30 September 2011

\begin{abstract}
Little attention has been paid to develop crab fishery in Sri Lanka though there is a potential for development of this industry in the coastal belt of the country. The most popular areas for crab fishery in Sri Lanka are Negombo, Chilaw, Batticaloa, Koggala, Tangall, Dikvalla and Trincomalee. This study was carried out in Koggala, Gall district to identify the socio-economic situation of crab growers; to investigate the harvesting, processing and marketing methods; to identify the issues related to livelihood of crab collectors and to make appropriate suggestions to overcome the recognized issues. Primary and secondary data were collected for the study.
\end{abstract}

Almost all the crab collectors who are living around the Koggala lagoon were personally interviewed to collect primary data. Variables related to socio-economics of the crab collectors were collected to analyze the situation. The descriptive statistics and Pearson's correlation test were employed to analyze the data. A majority of the crab collectors belonged to middle age category. Their education level was low and did not completely depend on crab fishery as the income source. They found to engage on various activities such as crab collecting, sea fishing and fish selling. Average annual income and income from crab collection were recorded as SLRs 177,960 (US \$ 1,618) and SLRs 76,560 (US \$ 696), respectively. However, a majority of crab collectors were in middle level wealth condition. Their monthly harvest ranged from 0 to $200 \mathrm{~kg}$ with an average of $35 \mathrm{~kg}$. All the crab collectors sold their production to regular buyers and to the tourist hotels. Further, crab collectors followed especial postharvest methods and categorize the harvest into three types depending on the size before selling.

Key words: Crab Fishery, Livelihood, Income

\section{INTRODUCTION}

Crab fishery, initiated as small scale industry in early $1990 \mathrm{~s}$ in villages close to Negombo lagoon, has now become a profitable industry in several areas in the coastal belt of Sri Lanka. Crab fishery involves, capturing of just-molted crabs (water/ mud crabs) from wild and fattening under captivity with a variety of food such as fish offal, shark heads, cockles etc for 2 -3 weeks before harvesting for sale. Both sexes are used for fattening and the fattened crabs are sold to local market and for export to Southeastern and Pacific countries. This industry is very popular among the small-scale fish farmers due to simple technology involved, low investment required and high profit margins.

In Sri Lanka, the area under brackish water estimated to be around 120,000ha of which 40,000 ha are shallow lagoons and mangrove swamps. These areas are endowed with rich

*Corresponding author: sandika@agecon.ruh.ac.lk bottom fauna and flora, a potential source for fattening of mud crabs (Caddya and Cochrane 2001). At present, there are no established crab culture or fattening farms in Sri Lanka. In view of the increasing demand for crabs for export market, Sri Lanka can explore its full potential to initiate an organized crab culture and fattening industry (Chin-How-Cheong and Anandakoon 1991). Currently the most popular areas for crab culture in Sri Lanka are Negombo, Chilaw, Batticaloa, and Trincomalee.

This study was done in Koggala, Galle to identify the socio-economic situation of crab growers; to determine methods used for harvesting, processing and marketing; to identify the issues related to livelihood and to make appropriate suggestions to overcome the recognized issues. The study will help concerned policy makers to evolve and inculcate appropriate livelihood development approaches in order to enhance the wellbeing of this community. 


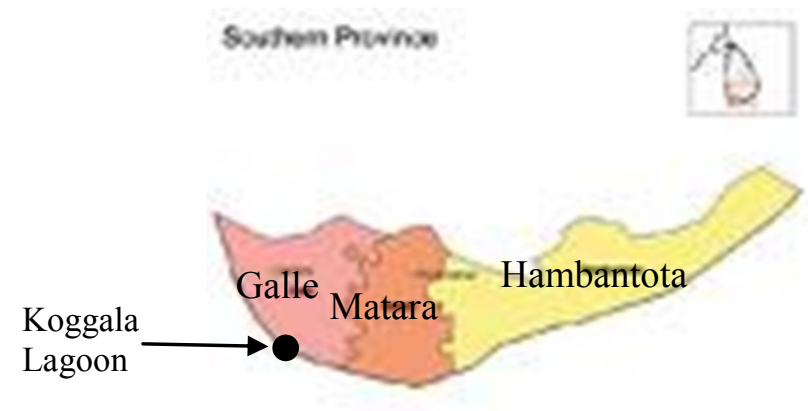

Figure 1: Study Location METHODOLOGY

The study was conducted in Koggala lagoon in Galle district in the Southern province Sri Lanka (Fig 1). Crab collectors who live around Koggala lagoon were interviewed to collect primary data. Primary data was collected by observations and personal interview with the help of an interview schedule. Additional information was collected through systematic field observation. Of the 35 crab collectors, 30 were interviewed. In addition, past research articles were used to obtain secondary information.

Information on age, education, family size, income, family education background, wealth of the family, nature of the occupation, experience, major cost components for the occupation, seasonality of occupation, amount of harvest, selling amount, post harvest methods and processing, market place, price, training received, job satisfaction, occupational related health hazards, membership of societies and source of credits were collected. Method developed by Sandika (2009) and Sandika and Withana (2010) were used to measurer the selected variables. The empirical measurement of the selected variables are given in Table 1 . The descriptive statistics such as mean, percentage and Pearson's correlation test were used to analyze the data.

\section{RESULTS AND DISCUSSION}

\section{Socio-economic characteristics of crab collectors}

Age of the crab collectors ranged from 17 to 74 years with a mean of 43.9. The education level found to be low, with a majority $(56 \%)$ studied up to primary (Grade 5) level. The mean family size determined to be 6 (range 2 - 9). These findings are in agreement with those of
Sandika (2009) and Sandika and Withana (2010). This indicates that poor interest of young people for crab culture. Income is the most important factor for the sustainability of any livelihood. The respondents' income found to be a composite of various activities. Most of the respondents engaged in crab collecting, sea fishing and fish selling to ensure sufficient income for their daily expenditure. Annual income of the crab collectors ranged from SLRs 72,000 (US\$ 655) to SLRs. 480,000 (US\$ 4,364) (US\$ $1=$ SLRs 110) with an average of SLRs 177,960 (US\$ 1,617). Average annual income from crab collection alone recorded as SLRs 76,560 (US\$ 696). These figures were in agreement with those given by Samonte and Agbayani (1992) - from SLRs 24,000 (US\$ 218) to Rs. 240,000 (US\$ 2182). The contribution from crab culture to total income found to be $8-100 \%$ with an average of $46 \%$.

Family education background is other important socio-economic indicator to measure the living condition of the respondents. Education levels of the family members' were measured by developing family education index. It was noticed that a majority $(57 \%)$ of the crab collectors' family education was low. Nevertheless, wealth of the family is other important socio-economic indicator to measure the living condition. Family wealth was measured by developing family wealth index with including the house type, facilities, family vehicle, electrical and other equipment. Family wealth of the respondents was relatively high. Majority of crab collectors $(70 \%)$ were in middle level wealth condition. The important feature of this category was that they have permanent house with tile floor, brick and cement wall, tile or asbestos sheets, radio, television, telephone (mobile or land), basic furniture for their house and at least a motor cycle as family vehicle. These results prove that their economic and wealth condition is satisfactory because their earnings were relatively high. It is therefore, suggested that crab collection is good income sources for unemployed low educated youth.

\section{Job related characteristics of crab collectors}

All crab collectors indicated that their father or grandfather engaged in similar occupation and 
Table 2: Socioeconomic characters of mushroom crab collectors

\begin{tabular}{|c|c|c|c|c|}
\hline Variables & \multicolumn{4}{|c|}{ Categories with Percentages (\%) } \\
\hline 1. Age (Year) & Young $(30 \%)$ & Middle $(42 \%)$ & Old $(28 \%)$ & Total $(100 \%)$ \\
\hline 2. Education (Grade) & Primary $(56 \%)$ & Grade $6-9(44 \%)$ & Ordinary/Advance Level $(0 \%)$ & Total $(100 \%)$ \\
\hline 3. Experience & $\begin{array}{l}\text { Low }(23 \%) \\
(<15 \text { year })\end{array}$ & Medium (50\%) (16-30 year) & High $(27 \%)(31<$ year $)$ & Total $(100 \%)$ \\
\hline 4. Family background & $\begin{array}{l}\text { Low }(57 \%) \\
(<17 \text { score })\end{array}$ & Medium (37\%) (18-34 score & High $(06 \%)(35<$ score $)$ & Total $(100 \%)$ \\
\hline 5. Family wealth & $\begin{array}{l}\text { Low }(3 \%) \\
(<11 \text { score })\end{array}$ & Medium (70\%) (12-22 score) & High $(27 \%)(23<$ score $)$ & Total $(100 \%)$ \\
\hline
\end{tabular}

Table 3: Job related information

\begin{tabular}{lllll}
\hline \multicolumn{1}{c}{ Variables } & \multicolumn{4}{c}{ Categories with Percentage (\%) } \\
\hline 1. Job experience & Low (15year) (23\%) & Medium (16-32) (50\%) & High (33< year) $(27 \%)$ & Total $(100 \%)$ \\
2. Harvest (kg/month) & $<40(80 \%)$ & $41-80(13 \%)$ & $81-200(7 \%)$ & Total $(100 \%)$ \\
3. Job Satisfaction & Dissatisfy $(23 \%)$ & Indifferent $(50 \%)$ & Satisfy $(27 \%)$ & Total $(100 \%)$ \\
4. Memberships* & Fish cooperative (60\%) Welfare society $(40 \%)$ & Non members $(40 \%)$ & Total $(100 \%)$ \\
5. Accessibility to credit & Yes $(50 \%)$ & No (50\%) & Total $(100 \%)$ \\
\hline
\end{tabular}

recognition for their occupation were the possible reasons for their low satisfaction level though their income was high. It is therefore, needed to take appropriate measures by the relevant authorities not only to increase job satisfaction of the respondents but also to solve their problems. Membership of the societies shows the strength of social capital of the respondents. About $60 \%$ of respondents have taken the membership of the fishery cooperative society while $40 \%$ of them have recorded as member of social welfare societies which are functioning in their villages. This should be taken into account by the policy makers, researchers and other social mobilizers to organize them before any research or community development activity.

Access to credits is one of major requirements to develop the livelihood of any society. About $50 \%$ crab collectors have not taken any credit from out sources (Table 3). It shows the reluctance to take credit for their livelihood development. They have further mentioned that their income was sufficient and their negative attitudes towards further development. That was due to their low education level. It is therefore, important to change their negative attitudes towards the development by conducting the appropriate training programs. On the other hand, $50 \%$ of respondents have taken loans for their livelihood development. The loan amounts taken by the crab collectors have varied from Rs 10,000 (US \$ 91) to 30,000 (US \$ 273). Majority have taken the loan from Samurdhi Bank. Others have taken from private and NGOs base formal institutes.

\section{Correlation among the different variables}

Age and experience of the respondents were positively correlated $(\mathrm{r}=0.7, \mathrm{p}=0.00)$. Monthly income was significantly and positively correlated with income from other sources $(\mathrm{r}=0.85, \mathrm{p}=0.00)$. With regard to the cost of the crab collection, fixed cost was significantly and positively correlated $(\mathrm{r}=0.47, \mathrm{p}=0.02)$ to the total cost. It clearly explains that major cost of crab collection was capital cost such as boat nets etc. Further, operational cost was very low. Other important point is that income of crab collection was significantly correlated with the fixed cost $(\mathrm{r}=0.39, \mathrm{p}=0.03)$. Therefore, It can be clarified that the person who can expend more for capital items such as for boat, nets, hand nets, snare and floaters etc will be help to earn more than others. The significantly positive correlation $(\mathrm{r}=.40 \mathrm{p}=0.02)$ was shown between membership of the communities or organizations and accessibility to formal credit. It means that join to community society will be help to get the formal credits (Table 4).

\section{Issues related to livelihood}

A high majority $(76.7 \%)$ of collectors have mentioned that mixing of sea water with the lagoon water due to frequently opening of sand bar of the lagoon (Table 4). According to respondents, this was not frequently occurred previously. The possible reason for the situation was not recognized. So, further research needs to be done to recognize the reasons. They have mentioned further, it leads poor breeding of the crab. There was no any 
Table 4: Correlation values

\begin{tabular}{|c|c|c|}
\hline Variables & r value & P value \\
\hline 1. Age and experience & $\mathrm{r}=0.7$ & $\mathrm{P}=0.00$ \\
\hline $\begin{array}{l}\text { 2. Monthly income and income from } \\
\text { other sources }\end{array}$ & $\mathrm{r}=0.85$ & $\mathrm{P}=0.00$ \\
\hline 3. Fixed cost and total cost & $\mathrm{r}=0.47$ & $\mathrm{P}=0.02$ \\
\hline 4. Crab collection and fixed cost & $\mathrm{r}=0.39$ & $\mathrm{P}=0.03$ \\
\hline $\begin{array}{l}\text { 5. Membership of the communities or } \\
\text { organizations and accessibility to } \\
\text { formal credit }\end{array}$ & $r=0.4$ & $\mathrm{P}=0.02$ \\
\hline
\end{tabular}
action taken to control this issue so far by relevant authorities. It is therefore need to make an appropriate measure to prevent the situation. Almost equal present $(10 \%)$ have indicated that low harvest and harvesting of immature crab as second problem. People tend to collect the immature crab due to low harvest.

All respondents mentioned that making barrier to control flow of sea water in to lagoon is the ideal strategy to control the situation. It is therefore recommend to the relevant authorities to carry out a research with the purpose of make cost effective, social and environment sound solution for this issue. It further would be helped to safe the biodiversity too in the lagoon. Moreover, respondent have suggested that imposing by introducing appropriate regulation to protect the breeding areas of crab and immature crab. Therefore, this should be taken into care by the relevant institutes and authorities. In addition, educational campaigns can be organized as an alternative method to educate the people who collect the immature crab.

As adopted in inland fisheries and Shrimp farming industries, introducing artificially bred immature crab to lagoon is also a possible solution to overcome the problem of natural breeding of crab. It is therefore suggested to conduct research on this matter to check the potential.

\section{CONCLUTION AND RECOMMENDATION}

Crab collectors' income is not completely dependent on one activity. Hence, their economic status is satisfactorily good. Major cost item of the livelihood of crab collectors were identified as cost for boat, nets, hand nets, floaters and baits etc. Even though the harvest is highly variable the average found to be $35 \mathrm{~kg} /$ month. This harvest provides significant
Table 4: Issues related to livelihood

\begin{tabular}{lc}
\hline Problem & $\begin{array}{c}\text { Percentag } \\
\text { e }\end{array}$ \\
\hline 1. Mixing of sea water with the lagoon water & 76.6 \\
2. Low harvest & 13.4 \\
3. Harvesting of immature crab & 10.0 \\
\hline
\end{tabular}

income for the respondents. Marketing of crab is not a major issue for collectors. Further, crab collectors have adopted to especial post harvest methods before selling their harvest.

Mixing of sea water with the lagoon water due to frequent opening of sand bar of the lagoon, poor breeding of the crab and low harvest lead to making suitable door which can control the sea water flow in to lagoon is the ideal strategy to control the situation.

It further would help maintain the biodiversity in the lagoon. It is suggested to introduce appropriate regulation to protect the breeding areas of crabs and immature crabs. Therefore, this should be taking into care by the relevant institutes and authorities. In addition, campaigns can be organized as an alternative method to educate the people who are collecting the immature crab. Further, impotence of adopting appropriate strategy to manage the fisheries resources was highlighted by the many researchers. Introducing artificially bred immature crab to lagoon to overcome the problem of natural breeding is one possible suggestion that requires inputs from research

\section{ACKNOWLEDGMENTS}

This study was supported by a grant from Sri Lanka National Commission for UNESCO Participation Program 2008-2009.

\section{REFERENCES}

Caddya JF and Cochrane KL 2001 A review of fisheries management past and present and some future perspectives for the third millennium. Journal of Ocean \& Coastal Management 44: 653-682.

Chin-How-Cheong and Amandakoon HP 1991 Status, Constraints and potential of mud crab fishery and culture in Sri Lanka. In: CA Angell (ed.) The mud crab. A report on the seminar convened in Surat Thani, Thailand 201-202.

Derek SJ 2006 Category, narrative, and value in the governance of small-scale fisheries, Journal of 
Marine Policy 30: 747-756.

Marichamy R 1996 Crab farming potential in India, Proceedings of the Seminar on Fisheries A Multibillion Dollar Industry, Madras Aug 1719, 1995.115-122.

Samante PB and Agbayani RF 1992 Pond culture of mud crab (Scylla serrata) An economic analysis, In: CA Angell (ed.) The mud crab. A report on the seminar convened in Surat Thani, Thailand 201-202.

Sandika AL 2009 Exploration of entrepreneurial behaviour of small-scale mushroom growers in Matara District, Competitive Management in a Dynamic World, Faculty of Management \&
Finance, University of Colombo, Sri Lanka 349356.

Sandika AL and Withana NRP 2010 Economic analysis of chena cultivation in Monaragala District, Sri Lanka, Proceedings of the Fifteenth International Forestry and Environment Symposium 2010 University of Sri Jayawardhanapura Sri Lanka. 350 - 356.

Sathiadhas R and Najmudeen TM 2004 Economic evaluation of mud crab farming under different production systems in India, Journal of Aquaculture Economics \& Management 8 (2): 99 -110 . 